Published in final edited form as:

Int J Cardiol. 2016 July 1; 214: 428-437. doi:10.1016/j.ijcard.2016.03.215.

\title{
Use of Antegrade Dissection Re-entry in Coronary Chronic Total Occlusion Percutaneous Coronary Intervention in a Contemporary Multicenter Registry
}

\author{
Barbara Anna Danek, MD ${ }^{1,13}$, Aris Karatasakis, MD ${ }^{1,13}$, Dimitri Karmpaliotis, MD ${ }^{2,13}$, \\ Khaldoon Alaswad, MD ${ }^{3,13}$, Robert W. Yeh, MD ${ }^{4,13}$, Farouc A. Jaffer, MD, PhD ${ }^{4,13}$, Mitul \\ Patel, MD ${ }^{5,13}$, John Bahadorani, MD ${ }^{5,13}$, William L. Lombardi, MD ${ }^{6,13}$, Michael R. Wyman, \\ MD $^{7,13}$, J. Aaron Grantham, MD ${ }^{8,13}$, Anthony Doing, MD ${ }^{9,13}$, Jeffrey W. Moses, MD $^{2,13}$, Ajay \\ Kirtane, MD 2,13, Manish Parikh, MD ${ }^{2,13}$, Ziad Ali, MD2,13, Sanjog Kalra, MD'2,13, David E. \\ Kandzari, MD ${ }^{10,13}$, Nicholas Lembo, MD ${ }^{10,13}$, Santiago Garcia, MD ${ }^{11,13}$, Bavana V. Rangan, \\ BDS, MPH ${ }^{1,13}$, Craig A. Thompson, MD, MMSc ${ }^{12,13}$, Subhash Banerjee, MD ${ }^{1,13}$, and \\ Emmanouil S. Brilakis, MD, PhD ${ }^{1,13}$ \\ ${ }^{1}$ VA North Texas Healthcare System and UT Southwestern Medical Center, Dallas, TX
}

\footnotetext{
Corresponding Author: Emmanouil S. Brilakis, MD, PhD, Dallas VA Medical Center (111A), 4500 South Lancaster Road, Dallas, TX 75216, Tel: (214) 857-1547, Fax: (214) 302-1341, esbrilakis@ gmail.com.

13 This author takes responsibility for all aspects of the reliability and freedom from bias of the data presented and their discussed interpretation.
}

Publisher's Disclaimer: This is a PDF file of an unedited manuscript that has been accepted for publication. As a service to our customers we are providing this early version of the manuscript. The manuscript will undergo copyediting, typesetting, and review of the resulting proof before it is published in its final citable form. Please note that during the production process errors may be discovered which could affect the content, and all legal disclaimers that apply to the journal pertain.

Disclosures

Dr. Danek: none.

Dr. Karatasakis: none.

Dr. Karmpaliotis: speaker bureau, Abbott Vascular, Medtronic, and Boston Scientific

Dr. Alaswad: consulting fees from Terumo and Boston Scientific; consultant, no financial, Abbott Laboratories.

Dr. Yeh: Career Development Award (1K23HL118138) from the National Heart, Lung, and Blood Institute.

Dr. Jaffer: consultant to Boston Scientific, Siemens, and Merck, nonfinancial research support from Abbott Vascular, research grant from National Institutes of Health (HL-R01-108229).

Dr Patel: none.

Dr Bahadorani: none.

Dr. Lombardi: equity with Bridgepoint Medical.

Dr. Wyman: Honoraria/consulting/speaking fees from Boston Scientific, Abbott Vascular, and Asahi.

Dr. Grantham: Speaking fees, consulting, and honoraria from Boston Scientific, Asahi Intecc. Research grants from Boston Scientific, Asahi Intecc, Abbott Vascular, Medtronic.

Dr. Doing: none. Dr. Moses: none.

Dr. Kirtane: Institutional research grants to Columbia University from Boston Scientific, Medtronic, Abbott Vascular, Abiomed, St. Jude Medical, Vascular Dynamics, Glaxo SmithKline, and Eli Lilly.

Dr. Parikh: none.

Dr. Ali: grant support and is a consultant for St. Jude Medical and InfraRedX. Dr. Kalra: none.

Dr. Kandzari: research/grant support and consulting honoraria from Boston Scientific. and Medtronic Cardiovascular, and research/ grant support from Abbott.

Dr. Lembo: speaker bureau: Medtronic; advisory board Abbott Vascular and Medtronic.

Dr. Garcia: consulting fees from Medtronic.

Dr. Rangan: none.

Dr. Thompson: employee of Boston Scientific.

Dr. Banerjee: research grants from Gilead and the Medicines Company; consultant/speaker honoraria from Covidien and Medtronic; ownership in MDCARE Global (spouse); intellectual property in HygeiaTel.

Dr. Brilakis: consulting/speaker honoraria from Abbott Vascular, Asahi, Boston Scientific, Elsevier, GE Healthcare, St Jude Medical, and Terumo; research support from Boston Scientific and InfraRedx; spouse is employee of Medtronic. 
${ }^{2}$ Columbia University, New York, NY

${ }^{3}$ Henry Ford Hospital, Detroit, MI

${ }^{4}$ Massachusetts General Hospital and Harvard Medical School, Boston, MA

${ }^{5}$ VA San Diego Healthcare System and University of California San Diego, San Diego, CA

6University of Washington, Seattle, WA

${ }^{7}$ Torrance Memorial Medical Center, Torrance, CA

${ }^{8}$ Mid America Heart Institute, Kansas City, MO

${ }^{9}$ Medical Center of the Rockies, Loveland, CO

${ }^{10}$ Piedmont Heart Institute, Atlanta, GA

${ }^{11}$ Minneapolis VA Healthcare System and University of Minnesota, Minneapolis, MN

${ }^{12}$ Boston Scientific, Natick, MA

\section{Abstract}

Background-We assessed efficacy and safety of chronic total occlusion (CTO) percutaneous coronary intervention (PCI) using antegrade dissection re-entry (ADR).

Methods-We examined outcomes of ADR among 1,313 CTO PCIs performed at 11 US centers between 2012-2015.

Results $-84.1 \%$ of patients were men. Prevalence of prior coronary artery bypass graft surgery was $34.3 \%$. Overall technical and procedural success were $90.1 \%$ and $88.7 \%$, respectively. Inhospital major adverse cardiovascular events (MACE) occurred in 31 patients (2.4\%).

ADR was used in 458 cases (34.9\%), and was the first strategy in 169 cases (12.9\%). ADR cases were angiographically more complex than non-ADR cases (mean J-CTO score: $2.8 \pm 1.2$ vs.

$2.4 \pm 1.2, \mathrm{p}<0.001)$. ADR was performed using the CrossBoss catheter in 246 of $458(53.7 \%)$ and the Stingray system in 251 ADR cases (54.8\%). Compared with non-ADR cases, ADR cases had lower technical ( $86.9 \%$ vs. $91.8 \%, \mathrm{p}=0.005)$ and procedural success $(85.0 \%$ vs. $90.7 \%, \mathrm{p}=0.002)$, but similar risk for MACE ( $2.9 \%$ vs. $2.2 \%, \mathrm{p}=0.42$ ). ADR was associated with longer procedure and fluoroscopy time, and higher patient air kerma dose and contrast volume (all $\mathrm{p}<0.001$ ). After excluding retrograde cases, ADR and antegrade wire escalation (AWE) had similar technical success $(92.7 \%$ vs. $94.2 \%, \mathrm{p}=0.43)$ procedural success $(91.8 \%$ vs. $94.1 \%, \mathrm{p}=0.23)$, and MACE ( $2.1 \%$ vs. $0.6 \%, \mathrm{p}=0.12)$.

Conclusions-ADR is used relatively frequently in contemporary CTO PCI, especially for challenging lesions and after failure of other strategies. ADR is associated with similar success rates and risk for complications as compared with AWE, and is important for achieving high procedural success.

\section{Keywords}

chronic total occlusion; techniques; dissection and re-entry; outcomes; complications 


\section{Introduction}

Antegrade dissection and re-entry (ADR) for chronic total occlusion (CTO) percutaneous coronary intervention (PCI) was first described 10 years ago (1) and has since evolved to an indispensable technique (2). In the hybrid approach to CTO PCI, ADR is recommended as the initial crossing strategy in CTOs with unambiguous proximal cap and good quality distal vessel, when the occlusion length is estimated to be greater than 20 millimeters $(3,4)$. ADR is also commonly used after other crossing strategies fail (2). Antegrade dissection can be achieved with either a knuckled guidewire or the CrossBoss catheter (Boston Scientific, Nattick, Massachusetts) and antegrade re-entry can be achieved either using guidewires or with the Stingray system (Boston Scientific) (5-8). We examined a contemporary, multicenter CTO PCI registry to determine the current role of ADR and the associated outcomes.

\section{Methods}

\section{Study population}

We examined the clinical and angiographic records of patients who underwent CTO PCI between May 2012 and October 2015 at 11 US centers experienced in CTO PCI: Appleton Cardiology, Appleton, Wisconsin; Columbia University, New York, New York; Henry Ford Hospital, Detroit, Michigan; Massachusetts General Hospital, Boston, Massachusetts; Medical Center of the Rockies, Loveland, Colorado; Piedmont Heart Institute, Atlanta Georgia; PeaceHealth St.Joseph Medical Center, Bellingham Washington; St. Luke's Health System's Mid-America Heart Institute, Kansas City, Missouri; Torrance Memorial Center, Torrance, California; VA North Texas Health Care System, Dallas, Texas, and VA San Diego Healthcare System, San Diego, California. Data collection was performed prospectively and retrospectively and recorded in a dedicated CTO database (PROGRESS CTO, Clinicaltrials.gov Identifier: NCT02061436) (9-16). Some centers only enrolled patients during part of the study period due to participation in other studies. The study protocol conforms to the ethical guidelines of the 1975 Declaration of Helsinki and was approved by the institutional review board of each site.

\section{Definitions}

Coronary CTOs were defined as coronary lesions with thrombolysis in myocardial infarction (TIMI) grade 0 flow of at least 3 months duration. Estimation of the duration of occlusion was clinical, based on the first onset of angina, prior history of myocardial infarction in the target vessel territory, or comparison with a prior angiogram.

Calcification was assessed by angiography as mild (spots), moderate (involving $\mathbf{5 0 \%}$ of the reference lesion diameter) and severe (involving $>50 \%$ of the reference lesion diameter). Moderate proximal vessel tortuosity was defined as the presence of at least 2 bends $>70^{\circ}$ or 1 bend $>90^{\circ}$ and severe tortuosity as 2 bends $>90^{\circ}$ or 1 bend $>120^{\circ}$ in the CTO vessel. Interventional collaterals were defined as collaterals considered amenable to crossing by a guidewire and a microcatheter by the operator. Procedures in which antegrade dissection or antegrade re-entry or both were used at any time were classified as ADR procedures. A 
procedure was considered to be "primary ADR" if the first attempted crossing strategy was subintimal dissection with subsequent lumen re-entry distal to the lesion. A procedure was considered "secondary ADR" if ADR was performed after failure of another CTO crossing strategy. A procedure was considered "tertiary ADR" if ADR was used after two other failed crossing strategies. A procedure was considered retrograde if an attempt was made to cross the lesion through a collateral vessel supplying the target vessel distal to the lesion. AWEonly procedures were those that used an exclusively intimal antegrade approach, with no entry into the subintimal space. A procedure was considered "antegrade-only" if no retrograde crossing attempts were made.

Technical success of CTO PCI was defined as successful CTO revascularization with achievement of $<30 \%$ residual diameter stenosis within the treated segment and restoration of TIMI grade 3 antegrade flow. Procedural success was defined as the combination of technical success with no in-hospital major adverse cardiac events (MACE). In-hospital MACE included any of the following adverse events prior to hospital discharge: death, myocardial infarction, recurrent symptoms requiring urgent repeat target vessel revascularization with PCI or coronary artery bypass graft surgery (CABG), tamponade requiring either pericardiocentesis or surgery, and stroke. Myocardial infarction (MI) was defined using the Third Universal Definition of Myocardial Infarction (type 4 MI) (17).

\section{Statistical Analysis}

Categorical variables were expressed as percentages and compared using Pearson's chisquare test or Fisher's exact test. Continuous variables were presented as mean \pm standard deviation or median (interquartile range) and were compared using the t-test or Wilcoxon rank-sum test, as appropriate. Multivariable logistic regression analysis was performed to assess the association of baseline clinical and angiographic characteristics with technical success in the entire study population and with the use of ADR in the antegrade-only population. Variables associated with technical success and use of ADR, respectively, with $\mathrm{p}<0.10$ were included in the multivariate models. All statistical analyses were performed with JMP 12.0 (SAS Institute, Cary, North Carolina). A two-sided $p$-value of 0.05 was considered statistically significant.

\section{Results}

\section{Baseline clinical and angiographic characteristics}

A total of 1,313 CTO PCIs performed in 1,288 patients were included in the present analysis. ADR was used in 458 procedures (34.9\%). Mean age of the study patients was $65.5 \pm 10.2$ years, and $84.1 \%$ were men with high prevalence of hypertension (89.5\%), hyperlipidemia (94.3\%) and diabetes mellitus (45.0\%) (Table 1). Patients in whom ADR was used were significantly more likely to be men $(88.0 \%$ vs. $82.0 \%, \mathrm{p}=0.005)$, and have a history of heart failure ( $31.4 \%$ vs. $26.2 \%$, $\mathrm{p}=0.05$ ), prior $\mathrm{CABG}(38 \%$ vs. $32.3 \%$, $\mathrm{p}=0.04$ ), and prior CTO PCI failure (20.7\% vs. $16.0 \%, \mathrm{p}=0.04)$.

Compared with lesions attempted only with AWE and/or retrograde crossing, lesions attempted with ADR were more likely to be located in the right coronary artery (64.3\% vs. 
$53.0 \%$, p $<0.001)$, have longer length [median length: $30(22-50) \mathrm{mm}$ vs. $28(18-40) \mathrm{mm}$, $\mathrm{p}<0.001$ ] , and moderate or severe tortuosity $(39.6 \%$ vs. $33.0 \%, \mathrm{p}=0.02)$. They were also less likely to have interventional collaterals $(54.4 \%$ vs. $63.9 \%, \mathrm{p}=0.004)$ and more likely to have a higher J-CTO score $(2.8 \pm 1.2$ vs. $2.4 \pm 1.2, \mathrm{p}<0.001)$ (Table 1$)$.

\section{Procedural outcomes}

Technical and procedural success among all 1,313 cases was $90.1 \%$ and $88.7 \%$, respectively. Use of ADR was associated with lower technical ( $86.9 \%$ vs. $91.8 \%, \mathrm{p}=0.005)$ and procedural $(85.0 \%$ vs. $90.7 \%, \mathrm{p}=0.002)$ success (Figure 1A). Intravascular ultrasonography (IVUS) was used more commonly in cases involving ADR (50.2\% vs. $30.8 \%, \mathrm{p}<0.001)$, which also required more stents per lesion ( $2.9 \pm 1.1$ vs. $2.3 \pm 1.0, \mathrm{p}<0.001)$ (Table 2). ADR was associated with longer procedure time, longer fluoroscopy time, higher patient air kerma (kinetic energy released per unit mass) dose, and higher contrast volume ( $\mathrm{p}<0.001$ for all) (Table 2).

We performed multivariate analysis in the full study cohort $(n=1,313)$ to assess the impact of strategy selection on technical outcome. Variables associated with technical success in univariate analysis with $\mathrm{p}<0.10$ were included in the multivariate model (Figure 2A). The following were independent predictors of technical outcome (technical success or failure): prior MI (odds ratio [OR] 0.51, 95\% CI: 0.29-0.87, $\mathrm{p}=0.013$ ), the presence of interventional collaterals (OR 3.31, 95\% CI: 1.88-5.90, <0.001) and use of the retrograde approach (OR 0.48, 95\% CI: 0.26-0.89, $\mathrm{p}=0.020$ ). Although technical success was lower with use of ADR in this cohort (Figure 1A), multivariate analysis demonstrated that use of ADR was not independently associated with technical failure.

In-hospital major adverse cardiovascular events (MACE) occurred in 31 patients (2.4\%). No significant difference was found in the rates of MACE between the ADR and non-ADR groups (Figure 1A), with the exception of tamponade requiring emergency pericardiocentesis, which was more common in the ADR group $(1.8 \%$ vs. $0.1 \%, \mathrm{p}<0.001)$ (Table 2). Of the 8 perforations that occurred in the ADR group, 3 were caused by use of the CrossBoss catheter. In the first case, the CrossBoss exited the side of an old stent during crossing of an in-stent restenosis CTO. The CTO was crossed using the retrograde approach and the perforation was successfully sealed with a covered stent. In the second case, a perforation of the mid right coronary artery was occurred during attempted antegrade crossing using the CrossBoss catheter and was successfully treated with pericardiocentesis and prolonged balloon inflation. In the third case, perforation occurred during attempts to cross a right coronary artery CTO with the CrossBoss catheter; it was also treated with pericardiocentesis and prolonged balloon inflation. In the remaining five cases, perforation was due to epicardial collateral rupture $(n=2)$, wire perforation of a side branch (Figure 3), use of rotational atherectomy, and balloon rupture during post-dilation of a stent.

\section{Comparison of antegrade techniques}

After excluding 546 cases that used the retrograde approach, 767 antegrade-only cases remained. As compared with AWE-only cases, cases in which ADR was used involved longer lesions [30 (22-40) vs. $23(15-34) \mathrm{mm}, \mathrm{p}<0.001]$ and higher J-CTO score $(2.5 \pm 1.1 \mathrm{vs.}$ 
$1.9 \pm 1.2, \mathrm{p}<0.001$ ) (Table 3). There was no significant difference between technical success, procedural success, or MACE between the ADR and AWE-only cases (Table 4) (Figure 1B).

In addition, we performed multivariate analysis of the antegrade-only cohort $(n=767)$ in order to understand the impact of baseline differences between the ADR and AWE-only groups. Variables that were associated with use of ADR with $p<0.10$ were included in the multivariate model (Figure 2B). Two independent predictors of the use of ADR were identified: lesion length (odds ratio [OR] per mm length $=1.02,95 \%$ CI: $1.01-1.03, \mathrm{p}<0.001$ ) and J-CTO score (OR per point=1.31, 95\% CI: 1.09-1.57, $\mathrm{p}=0.004$ ).

\section{Antegrade sequence and outcomes}

ADR was used as the first crossing strategy in 169 cases (36.9\%) of ADR cases, while in the remaining 289 cases ADR was used after failure of another strategy (Figure 4). Of these, ADR was used as a second crossing strategy in 217 cases and as a third strategy in 65 cases. In cases where ADR was used as a second- and third-line strategy, technical success of the second and third crossing attempts was high (59.4\% and 70.3\%, respectively). Overall technical and procedural success was higher among cases that used ADR as a primary crossing strategy as compared with cases in which ADR was used after failure of another strategy $(91.7 \%$ vs. $84.1 \%, \mathrm{p}=0.02$, and $90.4 \%$ vs. $81.8 \%, \mathrm{p}=0.01$, respectively). When compared with secondary ADR, primary ADR cases were significantly less likely to have moderate or severe calcification $(53.7 \%$ vs. $64.9 \%, \mathrm{p}=0.02)$, moderate or severe tortuosity ( $31.5 \%$ vs. $44.2 \%, \mathrm{p}=0.008$ ), proximal cap ambiguity ( $20.4 \%$ vs. $32.8 \%, \mathrm{p}=0.02)$, and be due to in-stent restenosis $(20.3 \%$ vs. $9.4 \%, \mathrm{p}=0.001)$. Primary ADR cases were associated with shorter procedure time and smaller contrast volume [116.5 (89.3-158.0) minutes vs. 184.5 (127.0-234.0) minutes, $\mathrm{p}<0.001$, and $270(200-365) \mathrm{mL}$ vs. $350(250-442.5) \mathrm{mL}$, $\mathrm{p}<0.001$, respectively].

A CrossBoss microcatheter was used more frequently among primary ADR cases than nonprimary ADR ( $75.6 \%$ vs. $41.0 \%, \mathrm{p}<0.001)$ and was also more frequently associated with successful crossing in the primary ADR group (51.8\% vs. $23.5 \%$, p $<0.001)$. The knuckle wire technique was used more frequently among non-primary ADR as compared with primary ADR cases $(48.6 \%$ vs. $34.5 \%$, $\mathrm{p}<0.01)$. The knuckle wire technique was more frequently associated with successful crossing when ADR was not the primary crossing strategy (30.7\% vs. $11.3 \%, \mathrm{p}<0.001)$. There was no significant difference between MACE rates in the primary ADR group vs. the secondary/tertiary ADR group (Table 5).

\section{Dissection and re-entry strategies}

The CrossBoss catheter was used in 246 of 458 ADR cases (53.7\%) and was associated with shorter procedure time [144.5 (103.5-203.8) vs. 175.5 (122.3-235.3) minutes, $\mathrm{p}<0.001]$, smaller contrast volume [300 (225-399) vs. 340 (240-450) $\mathrm{mL}, \mathrm{p}=0.03$ ] and shorter fluoroscopy time [51.8 (31.4-80.4) vs. 63.8 (44.1-97.5) minutes, $\mathrm{p}<0.001]$ (Table 6). Technical success was higher in the CrossBoss group ( $89.8 \%$ vs. $83.5 \%$, $\mathrm{p}=0.045$ ), but procedural success and MACE were similar.

Re-entry strategies used in ADR cases are summarized in Table 7. The Stingray re-entry system was used in 251 of 458 cases (54.8\%). The "stick and swap" technique was used in 
82 cases, the "bobsled" technique was used in 8 cases, and the subintimal transcatheter withdrawal (STRAW) technique was used in 2 cases. The most commonly used wire for the "stick and swap" technique was the Pilot 200 (Abbott Vascular, used in 59 of 82 cases).

\section{Discussion}

The major finding of our study is that ADR is used relatively frequently during contemporary CTO PCI and plays an important role in achieving high procedural success, while maintaining an overall low rate of procedural complications. Primary ADR cases were more efficient than secondary ADR cases, but had similar success rates.

Our study underscores the importance of ADR within the hybrid algorithm, both as a primary and as secondary/tertiary crossing strategy. ADR is preferred as a primary strategy for long ( $\geq 20 \mathrm{~mm}$ ) and complex lesions with a clear proximal and distal cap (3). ADR is also recommended for lesions that could not be crossed by use of other crossing strategies. The technical success associated with primary, secondary, and tertiary ADR was 56.2\%, 59.4\% and $70.3 \%$, respectively (Figure 3). ADR was used more commonly in more complex lesions, as evidenced by higher J-CTO score in both univariate and multivariate analyses.

Subintimal lesion crossing can be performed either with the knuckle wire technique or with controlled dissection using the CrossBoss microcatheter. Re-entry can be achieved spontaneously with subintimal tracking and re-entry (STAR); with contrast-guided STAR, during which injection of contrast aids in delineation of the dissection plane (18-20); miniSTAR, which involves minimal subintimal tracking and early re-entry (21); and limited antegrade subintimal tracking (LAST), during which a stiffer wire such as the Confianza Pro 12 (Asahi Intecc) or Pilot 200 (Abbott Vascular) is used to re-enter just distal to the lesion (2).

Use of the CrossBoss catheter was associated with high technical success and low MACE rates when used in patients with prior failed CTO PCI or failed primary crossing attempts (5, 22). In our study population, use of the CrossBoss catheter was associated with greater efficiency and technical success than wire-based techniques, without a significant difference in procedural success or MACE. CrossBoss was used more frequently among primary ADR cases than secondary/tertiary ADR cases, and was more efficient and successful in this setting than knuckle wires, which were used more frequently when ADR was used as a "bail-out" strategy. The role of the CrossBoss catheter for primary antegrade crossing is currently being investigated in the Comparison of a CrossBoss First Versus Standard Wire Escalation Strategy for Crossing Coronary Chronic Total Occlusion (CrossBoss First) trial (NCT02510547), which is randomizing 246 patients undergoing antegrade CTO crossing to AWE or primary ADR. The hypothesis of the CrossBoss First study is that upfront use of the CrossBoss will be more efficient in recanalizing coronary CTOs.

Re-entry using the Stingray system has been steadily evolving over time. There are several techniques that can enhance the likelihood of success, such as the STRAW (23) and the "double-blind stick and swap" technique (24). If all else fails, other approaches (such as the retrograde approach) may be needed to successfully cross the occlusion (25). In our registry, 
the Stingray system was used in $54.8 \%$ of ADR cases. Of the 251 procedures where the Stingray was used, 143 also involved use of the CrossBoss catheter. The "stick and swap" technique was used in 82 ADR cases, and was successful in 66, whereas STRAW was used in 2 cases. The "bobsled" technique, which involves moving the Stingray balloon distally within the subintimal space before re-attempting true lumen re-entry, was also used infrequently (in 8 cases).

The overall incidence of complications was similar with ADR and non-ADR cases, with the exception of perforation, which occurred more frequently in the ADR group. The CrossBoss catheter can cause perforation if inadvertedly advanced through a side branch. To minimize this risk the CrossBoss should be advanced only for short distances each time (to torque device acts as a "brake" preventing further advancement in cases of sudden "jump" of the catheter during the fast spin technique). Confirmation of catheter position within the vessel structure should be performed in two orthogonal views, before continuing forward advancement.

The CrossBoss catheter can be particularly useful for crossing CTOs due to in-stent restenosis (ISR) $(7,26)$. Among ADR cases in our study, the CrossBoss catheter was used to treat ISR with similar frequency as wire-based techniques $(15.9 \%$ vs. $10.6 \%, \mathrm{p}=0.10)$ but with numerically higher technical success as compared with wire-based techniques $(97.4 \%$ vs. $86.4 \%, \mathrm{p}=0.09$ ). As one complication case suggests, perforation is still possible when crossing CTOs due to ISR, as the CrossBoss may exit through stent struts (27), hence meticulous attention should be paid to the CrossBoss location in relation to the stent. There are, however, cases of successful sub-stent crossing and "crushing" of the prior stent with new stents, with favorable acute and long-term results (28).

Although there is limited published data on long-term outcomes of patients treated with ADR, one study that compared ADR using the contrast-guided STAR re-entry technique to a conventional antegrade strategy showed similar outcomes at a median of 779 days, with higher in-stent restenosis in longer lesions (29). Mogabgab et al compared the CrossBoss and Stingray re-entry system with all other crossing strategies, showing no significant difference in target lesion revascularization and MACE at 1.8 years (30). Galassi et al reported a $6.5 \%$ two-year target lesion revascularization rate among 100 patietns treated with the mini-STAR technique (31). Rinfret et al showed no significant impact on outcomes with use of dissection re-entry among 212 CTO PCIs (32). While technical and procedural success has been demonstrated, prospective studies with longer follow-up are needed to assess the long-term safety and efficacy of sub-intimal stenting. Although stenting in a false lumen created by sub-intimal dissection has been viewed with some skepticism, target lesion restenosis and re-occlusion at two years appears to be low and more likely to occur if TIMI 3 is not achieved $(31,33)$. The AngiographiC Evaluation of the Everolimus-Eluting Stent in Chronic Total Occlusions (ACE-CTO) study showed similar restenosis with ADR and AWE, although retrograde crossing (especially retrograde true-to-true puncture) was associated with lower restenosis rates (34). As new re-entry techniques allow operators to use shorter sub-intimal dissection tracks, it is expected that the short-term and long-term outcomes of ADR will continue to improve. 
A limitation of our study is the observational design. Because this was not a randomized study, baseline differences between the groups may have affected the frequency and outcomes of the use of ADR. Our results should be interpreted in light of this limitation, and future randomized controlled studies should address this topic. Moreover, this study includes procedures performed at high volume centers by highly skilled and experienced CTO operators, and thus our findings may not be broadly generalizable to less experienced operators. Some of the participating centers enrolled patients only during parts of the study period. There was no centralized angiographic core laboratory or clinical event adjudication which may have allowed for differences in the way that angiographic and clinical definitions were applied. Long-term clinical follow-up data was not available for all the patients included in the study, thus only acute procedural outcomes are presented.

\section{Conclusion}

In summary, ADR is used relatively frequently during contemporary CTO PCI and is important for achieving high rates of procedural success with acceptable risk for complications. Further refinement of ADR techniques and evidence from ongoing randomized controlled trials will further define the optimal role of ADR in CTO PCI.

\section{Acknowledgements}

Study data were collected and managed using REDCap electronic data capture tools hosted at University of Texas Southwestern Medical Center.1 REDCap (Research Electronic Data Capture) is a secure, web-based application designed to support data capture for research studies, providing 1) an intuitive interface for validated data entry; 2) audit trails for tracking data manipulation and export procedures; 3 ) automated export procedures for seamless data downloads to common statistical packages; and 4) procedures for importing data from external sources.

REDCap is supported by CTSA NIH Grant UL1-RR024982.

\section{References}

1. Colombo A, Mikhail GW, Michev I, Iakovou I, Airoldi F, Chieffo A, et al. Treating chronic total occlusions using subintimal tracking and reentry: the STAR technique. Catheter Cardiovasc Interv. 2005; 64:407-11; discussion 12. [PubMed: 15789384]

2. Michael TT, Papayannis AC, Banerjee S, Brilakis ES. Subintimal dissection/reentry strategies in coronary chronic total occlusion interventions. Circ Cardiovasc Interv. 2012; 5:729-38. [PubMed: 23074346]

3. Brilakis ES, Grantham JA, Rinfret S, Wyman RM, Burke MN, Karmpaliotis D, et al. A percutaneous treatment algorithm for crossing coronary chronic total occlusions. JACC Cardiovasc Interv. 2012; 5:367-79. [PubMed: 22516392]

4. Rangan BV, Kotsia A, Christopoulos G, Spratt J, Rinfret S, Banerjee S, et al. The Hybrid Approach for Intervention of Chronic Total Occlusions. Curr Cardiol Rev. 2015; 11:299-304.

5. Whitlow PL, Burke MN, Lombardi WL, Wyman RM, Moses JW, Brilakis ES, et al. Use of a novel crossing and re-entry system in coronary chronic total occlusions that have failed standard crossing techniques: results of the FAST-CTOs (Facilitated Antegrade Steering Technique in Chronic Total Occlusions) trial. JACC Cardiovasc Interv. 2012; 5:393-401. [PubMed: 22516395]

6. Drozd J, Strange J, Wysokinska A, Sobieszek G, Tomaszewski M. Percutaneous recanalisation of chronically occluded coronary arteries with the CrossBoss/Stingray system: first experience (report of three cases). Kardiol Pol. 2015; 73:711-21. [PubMed: 26390318]

\footnotetext{
${ }^{1}$ Harris PA, Taylor R, Thielke R, Payne J, Gonzalez N, Conde JG. Research electronic data capture (REDCap) - A metadata-driven methodology and workflow process for providing translational research informatics support. J Biomed Inform. 2009; 42(2):377-81.
} 
7. Papayannis A, Banerjee S, Brilakis ES. Use of the Crossboss catheter in coronary chronic total occlusion due to in-stent restenosis. Catheter Cardiovasc Interv. 2012; 80:E30-6. [PubMed: 22162302]

8. Wosik J, Shorrock D, Christopoulos G, Kotsia A, Rangan BV, Roesle M, et al. Systematic Review of the BridgePoint System for Crossing Coronary and Peripheral Chronic Total Occlusions. J Invasive Cardiol. 2015; 27:269-76. [PubMed: 26028653]

9. Alaswad K, Menon RV, Christopoulos G, Lombardi WL, Karmpaliotis D, Grantham JA, et al. Transradial approach for coronary chronic total occlusion interventions: Insights from a contemporary multicenter registry. Catheter Cardiovasc Interv. 2015; 85:1123-9. [PubMed: 25640902]

10. Christopoulos G, Karmpaliotis D, Alaswad K, Lombardi WL, Grantham JA, Rangan BV, et al. The efficacy of "hybrid" percutaneous coronary intervention in chronic total occlusions caused by instent restenosis: insights from a US multicenter registry. Catheter Cardiovasc Interv. 2014; 84:64651. [PubMed: 24585508]

11. Christopoulos G, Karmpaliotis D, Wyman MR, Alaswad K, McCabe J, Lombardi WL, et al. Percutaneous Intervention of Circumflex Chronic Total Occlusions Is Associated With Worse Procedural Outcomes: Insights From a Multicentre US Registry. Can J Cardiol. 2014; 30:1588-94. [PubMed: 25442459]

12. Christopoulos G, Menon RV, Karmpaliotis D, Alaswad K, Lombardi W, Grantham A, et al. The efficacy and safety of the "hybrid" approach to coronary chronic total occlusions: insights from a contemporary multicenter US registry and comparison with prior studies. J Invasive Cardiol. 2014; 26:427-32. [PubMed: 25198485]

13. Christopoulos G, Menon RV, Karmpaliotis D, Alaswad K, Lombardi W, Grantham JA, et al. Application of the "hybrid approach" to chronic total occlusions in patients with previous coronary artery bypass graft surgery (from a Contemporary Multicenter US registry). Am J Cardiol. 2014; 113:1990-4. [PubMed: 24793678]

14. Sapontis J, Christopoulos G, Grantham JA, Wyman RM, Alaswad K, Karmpaliotis D, et al. Procedural failure of chronic total occlusion percutaneous coronary intervention: Insights from a multicenter US registry. Catheter Cardiovasc Interv. 2015; 85:1115-22. [PubMed: 25557905]

15. Christopoulos G, Wyman RM, Alaswad K, Karmpaliotis D, Lombardi W, Grantham JA, et al. Clinical Utility of the Japan-Chronic Total Occlusion Score in Coronary Chronic Total Occlusion Interventions: Results from a Multicenter Registry. Circ Cardiovasc Interv. 2015; 8:e002171. [PubMed: 26162857]

16. Christopoulos G, Karmpaliotis D, Alaswad K, Yeh RW, Jaffer FA, Wyman RM, et al. Application and outcomes of a hybrid approach to chronic total occlusion percutaneous coronary intervention in a contemporary multicenter US registry. Int J Cardiol. 2015; 198:222-8. [PubMed: 26189193]

17. Thygesen K, Alpert JS, Jaffe AS, Simoons ML, Chaitman BR, White HD, et al. Third universal definition of myocardial infarction. Glob Heart. 2012; 7:275-95. [PubMed: 25689940]

18. Amsavelu S, Carlino M, Brilakis ES. Carlino to the rescue: Use of intralesion contrast injection for bailout antegrade and retrograde crossing of complex chronic total occlusions. Catheter Cardiovasc Interv. 2016

19. Carlino M, Ruparelia N, Thomas G, Brooks M, Uretsky BF, Brilakis ES, et al. Modified contrast microinjection technique to facilitate chronic total occlusion recanalization. Catheter Cardiovasc Interv. 2015

20. Carlino M, Figini F, Ruparelia N, Uretsky BF, Godino C, Latib A, et al. Predictors of restenosis following contemporary subintimal tracking and reentry technique: The importance of final TIMI flow grade. Catheter Cardiovasc Interv. 2015

21. Galassi AR, Tomasello SD, Costanzo L, Campisano MB, Barrano G, Ueno M, et al. Mini-STAR as bail-out strategy for percutaneous coronary intervention of chronic total occlusion. Catheter Cardiovasc Interv. 2012; 79:30-40. [PubMed: 21956876]

22. Werner GS, Schofer J, Sievert H, Kugler C, Reifart NJ. Multicentre experience with the BridgePoint devices to facilitate recanalisation of chronic total coronary occlusions through controlled subintimal re-entry. EuroIntervention. 2011; 7:192-200. [PubMed: 21646061] 
23. Smith EJ, Di Mario C, Spratt JC, Hanratty CG, de Silva R, Lindsay AC, et al. Subintimal TRAnscatheter Withdrawal (STRAW) of hematomas compressing the distal true lumen: a novel technique to facilitate distal reentry during recanalization of chronic total occlusion (CTO). $\mathrm{J}$ Invasive Cardiol. 2015; 27:E1-4. [PubMed: 25589704]

24. Christopoulos G, Kotsia AP, Brilakis ES. The Double-Blind Stick-and-Swap Technique for True Lumen Reentry After Subintimal Crossing of Coronary Chronic Total Occlusions. J Invasive Cardiol. 2015; 27:E199-202. [PubMed: 26332885]

25. Faisal Latif EB, Jose Emilio Exaire. Retrograde approach to successfully treat antegrade failure due to subintimal hematoma of a right coronary artery chronic total occlusion. Interventional Cardiology. 2015; 7:229-33.

26. Wilson WM, Walsh S, Hanratty C, Strange J, Hill J, Sapontis J, et al. A novel approach to the management of occlusive in-stent restenosis (ISR). EuroIntervention. 2014; 9:1285-93. [PubMed: 24650770]

27. Ntatsios A, Smith WHT. Exit of CrossBoss between stent struts within chronic total occlusion to subintimal space: Completion of case via retrograde approach with rendezvous in coronary. Journal of Cardiology Cases. 2014; 9:183-6.

28. Quevedo HC, Irimpen A, Abi Rafeh N. Succesful antegrade subintimal bypass restenting of instent chronic total occlusion. Catheter Cardiovasc Interv. 2015; 86:E268-71. [PubMed: 25914155]

29. Godino C, Latib A, Economou FI, Al-Lamee R, Ielasi A, Bassanelli G, et al. Coronary chronic total occlusions: mid-term comparison of clinical outcome following the use of the guided-STAR technique and conventional anterograde approaches. Catheter Cardiovasc Interv. 2012; 79:20-7. [PubMed: 21805559]

30. Mogabgab O, Patel VG, Michael TT, Fuh E, Alomar M, Rangan BV, et al. Long-term outcomes with use of the CrossBoss and stingray coronary CTO crossing and re-entry devices. J Invasive Cardiol. 2013; 25:579-85. [PubMed: 24184892]

31. Galassi AR, Boukhris M, Tomasello SD, Marza F, Azzarelli S, Giubilato S, et al. Long-term clinical and angiographic outcomes of the mini-STAR technique as a bailout strategy for percutaneous coronary intervention of chronic total occlusion. Can J Cardiol. 2014; 30:1400-6. [PubMed: 25442438]

32. Rinfret S, Ribeiro HB, Nguyen CM, Nombela-Franco L, Urena M, Rodes-Cabau J. Dissection and re-entry techniques and longer-term outcomes following successful percutaneous coronary intervention of chronic total occlusion. Am J Cardiol. 2014; 114:1354-60. [PubMed: 25242364]

33. Visconti G, Focaccio A, Donahue M, Briguori C. Elective versus deferred stenting following subintimal recanalization of coronary chronic total occlusions. Catheter Cardiovasc Interv. 2015; 85:382-90. [PubMed: 24740711]

34. Kotsia A, Navara R, Michael TT, Sherbet DP, Roesle M, Christopoulos G, et al. The AngiographiC Evaluation of the Everolimus-Eluting Stent in Chronic Total Occlusion (ACE-CTO) Study. J Invasive Cardiol. 2015; 27:393-400. [PubMed: 26332874] 

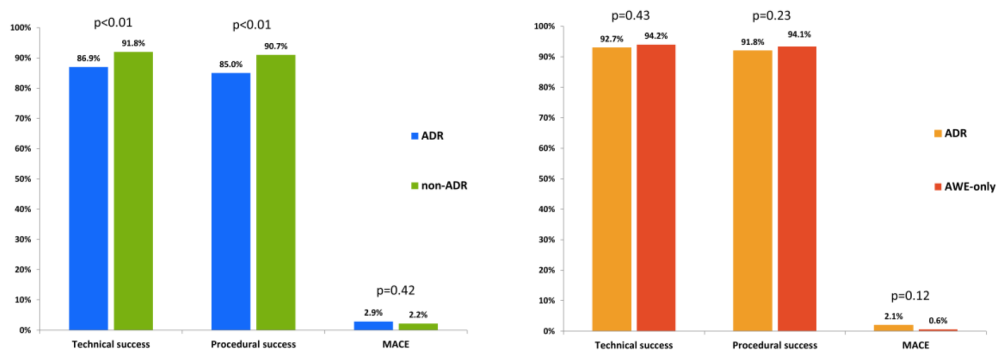

Figure 1.

A) All procedures: technical success, procedural success, and MACE according to use of ADR.

B) Antegrade-only procedures: technical success, procedural success, and MACE according to use of ADR. 

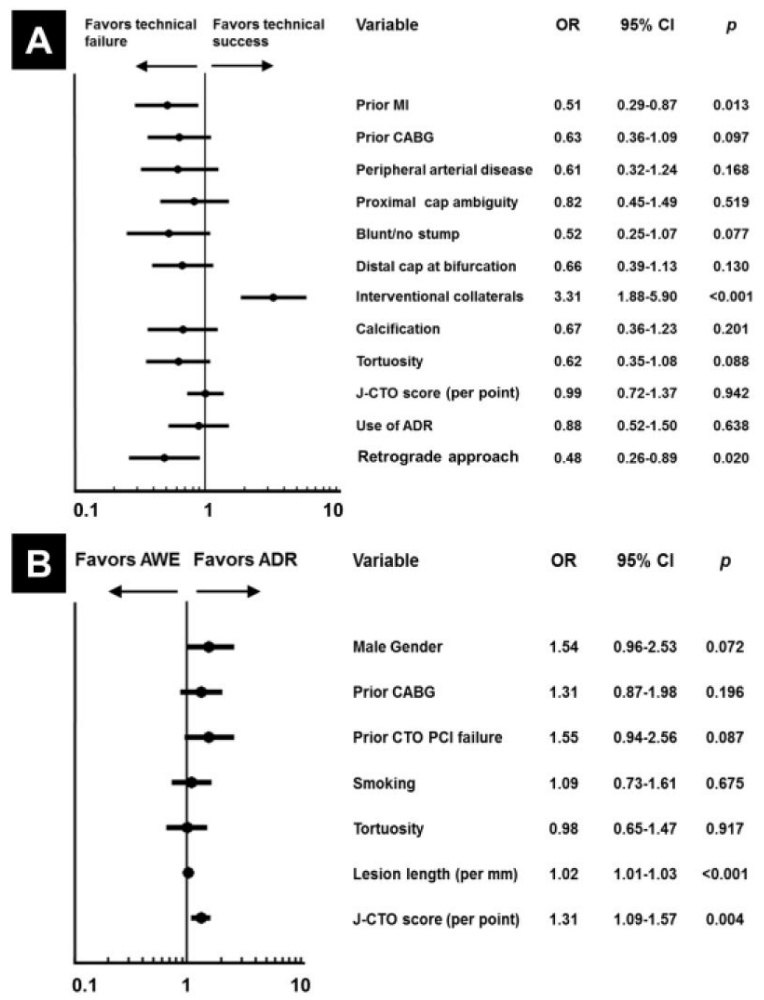

Figure 2.

A) Forest plot presenting the results of multivariate analysis of technical success in the entire study cohort.

B) Forest plot presenting the results of multivariate analysis of antegrade dissection re-entry selection in antegrade-only procedures.

OR, odds ratio; CI, confidence interval; MI, myocardial infarction; CABG, coronary artery bypass grafting; J-CTO score, Japanese Chronic Total Occlusion score; ADR, antegrade dissection re-entry; AWE, antegrade wire escalation; CTO, chronic total occlusion; PCI, percutaneous coronary intervention. 

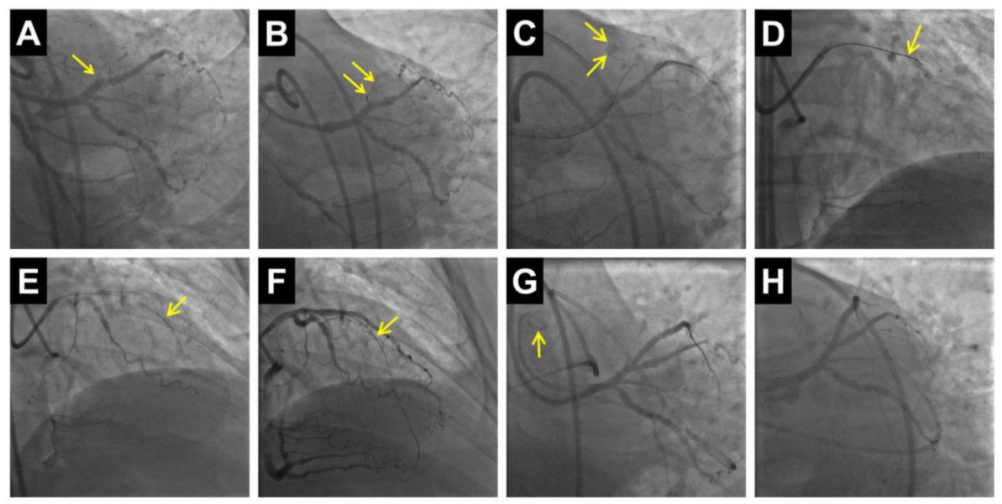

Figure 3. Illustrative case of coronary perforation

An attempt to cross a left anterior descending artery (LAD) chronic total occlusion (CTO) (arrow, panel A) was made using antegrade wire escalation through a Venture catheter (arrows, panel B). The wire entered a side branch and was withdrawn. Contrast staining was observed (arrows, panel C), without active bleeding. A guidewire was advanced subintimally through the occlusion (arrow, panel D), followed by the CrossBoss catheter (arrow, panel E). Re-entry was achieved using the Stingray balloon and guidewire (arrow panel F), followed by successful stent implantation. The patient developed hypotension and a pericardial effusion was seen requiring placement of a pigtail catheter (arrow, panel G). No active bleeding was observed at the perforation site. Protamine was administered after removal of the coronary guidewires (panel H). The patient had an uneventful recovery. 


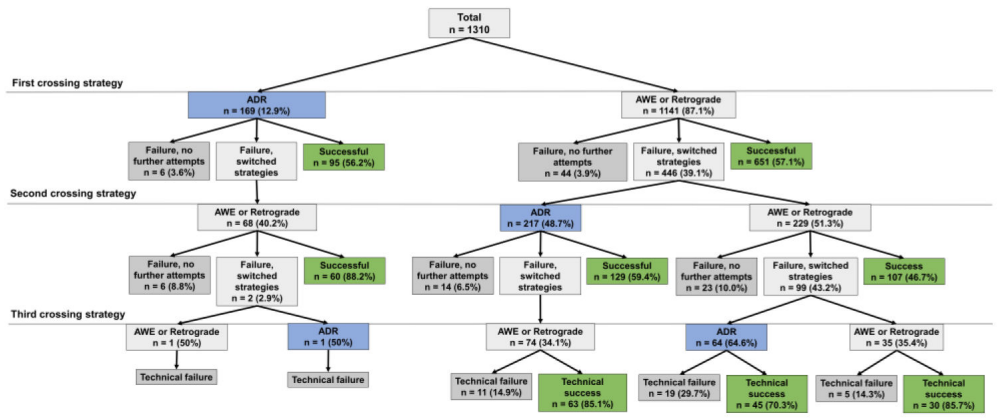

Figure 4.

Flow chart depicting the crossing strategies sequence used in the study population 


\section{Table 1}

Baseline and angiographic characteristics of the study lesions, classified according to use of antegrade dissection re-entry.

\begin{tabular}{|c|c|c|c|c|}
\hline Variable & Overall & $\begin{array}{c}\text { Antegrade } \\
\text { Dissection } \\
\text { Re-entry }\end{array}$ & $\begin{array}{l}\text { Non-Antegrade } \\
\text { Dissection } \\
\text { Re-entry }\end{array}$ & \\
\hline Clinical Characteristics & $n=1288$ & $n=452$ & $n=836$ & $p$ \\
\hline Age (years) ${ }^{*}$ & $65.5 \pm 10.2$ & $65.8 \pm 9.6$ & $65.4 \pm 10.5$ & 0.48 \\
\hline Men $(\%)$ & 84.1 & 88.0 & 82.0 & 0.005 \\
\hline Hypertension (\%) & 89.5 & 90.5 & 89.0 & 0.40 \\
\hline Hyperlipidemia (\%) & 94.3 & 95.5 & 93.6 & 0.16 \\
\hline Diabetes mellitus (\%) & 45.0 & 46.1 & 44.3 & 0.55 \\
\hline Smoking (\%) & 28.9 & 31.3 & 27.8 & 0.33 \\
\hline Heart failure (\%) & 28.0 & 31.4 & 26.2 & 0.05 \\
\hline History of MI (\%) & 41.8 & 44.0 & 40.6 & 0.25 \\
\hline History of CABG (\%) & 34.3 & 38.0 & 32.3 & 0.04 \\
\hline History of stroke (\%) & 11.0 & 10.8 & 64.8 & 0.86 \\
\hline Prior PCI (\%) & 64.9 & 65.0 & 64.8 & 0.93 \\
\hline Prior CTO PCI failure (\%) & 17.8 & 20.7 & 16.0 & 0.04 \\
\hline $\begin{array}{l}\text { Peripheral arterial } \\
\text { disease }(\%)\end{array}$ & 15.4 & 17.6 & 14.3 & 0.12 \\
\hline $\begin{array}{l}\text { Angiographic } \\
\text { Characteristics }\end{array}$ & $\mathrm{n}=\mathbf{1 3 1 3}$ & $\mathrm{n}=\mathbf{4 5 8}$ & $\mathrm{n}=\mathbf{8 5 5}$ & $p$ \\
\hline CTO target vessel & & & & $<0.001$ \\
\hline $\mathrm{RCA}(\%)$ & 56.9 & 64.3 & 53 & \\
\hline $\operatorname{LCX}(\%)$ & 19.8 & 14.2 & 22.8 & \\
\hline $\operatorname{LAD}(\%)$ & 23.3 & 21.5 & 24.2 & \\
\hline CTO length $(\mathrm{mm}){ }^{*}$ & $30(20-45)$ & $30(22-50)$ & $28(18-40)$ & $<0.001$ \\
\hline $\begin{array}{l}\text { Interventional collaterals } \\
(\%)\end{array}$ & 60.4 & 54.4 & 63.9 & 0.004 \\
\hline $\begin{array}{l}\text { Moderate/severe } \\
\text { calcification }(\%)\end{array}$ & 58.2 & 60.8 & 56.7 & 0.17 \\
\hline $\begin{array}{l}\text { Moderate/severe } \\
\text { tortuosity }(\%)\end{array}$ & 35.4 & 39.6 & 33 & 0.02 \\
\hline $\begin{array}{l}\text { Proximal cap ambiguity } \\
(\%)\end{array}$ & 31.3 & 28.7 & 32.8 & 0.19 \\
\hline In-stent restenosis (\%) & 14 & 13.5 & 14.4 & 0.64 \\
\hline J-CTO score ${ }^{*}$ & $2.6 \pm 1.2$ & $2.8 \pm 1.2$ & $2.4 \pm 1.2$ & $<0.001$ \\
\hline PROGRESS CTO score * & $1.2 \pm 1.0$ & $1.3 \pm 1.1$ & $1.2 \pm 1.0$ & 0.26 \\
\hline
\end{tabular}

CABG, coronary artery bypass graft surgery; IVUS, intravascular ultrasound; LVAD, left ventricular assist device; MACE, major adverse cardiovascular events; PCI, percutaneous coronary intervention mean \pm standard deviation or median (interquartile range). 


\section{Table 2}

Procedural characteristics and outcomes of all study lesions, classified according to use of antegrade dissection re-entry.

\begin{tabular}{|c|c|c|c|c|}
\hline Variable & Overall & $\begin{array}{c}\text { Antegrade } \\
\text { Dissection } \\
\text { Re-entry }\end{array}$ & $\begin{array}{l}\text { Non-Antegrade } \\
\text { Dissection } \\
\text { Re-entry }\end{array}$ & \\
\hline $\begin{array}{l}\text { Procedural } \\
\text { Characteristics } \\
\text { and Outcomes }\end{array}$ & $n=1313$ & $\mathrm{n}=\mathbf{4 5 8}$ & $\mathrm{n}=\mathbf{8 5 5}$ & $p$ \\
\hline IVUS used (\%) & 37.6 & 50.2 & 30.8 & $<0.001$ \\
\hline Stenting $(\%)$ & 88.7 & 84.3 & 91.0 & $<0.001$ \\
\hline Number of stents ${ }^{*}$ & $2.5 \pm 1.1$ & $2.9 \pm 1.1$ & $2.3 \pm 1.0$ & $<0.001$ \\
\hline $\begin{array}{l}\text { Hemodynamic } \\
\text { support (LVAD) } \\
(\%)\end{array}$ & 4.5 & 4.4 & 4.5 & 0.92 \\
\hline $\begin{array}{l}\text { Fluoroscopy time } \\
(\min )^{*}\end{array}$ & $45.8(27.3-75.2)$ & $58.1(37.2-87.1)$ & $\begin{array}{c}38.45(23.7- \\
67.5)\end{array}$ & $<0.001$ \\
\hline $\begin{array}{l}\text { Patient air kerma } \\
\text { dose (Gray) }\end{array}$ & $3.5(2-5.4)$ & $4.1(2.6-6)$ & $3.0(1.7-5.0)$ & $<0.001$ \\
\hline $\begin{array}{l}\text { Procedure time } \\
(\mathrm{min})^{*}\end{array}$ & $126(85-186)$ & $\begin{array}{l}156.5(112.3- \\
216.8)\end{array}$ & $111(75-165)$ & $<0.001$ \\
\hline $\begin{array}{l}\text { Contrast volume } \\
(\mathrm{ml})^{*}\end{array}$ & $260(200-360)$ & $310(226-411)$ & $250(180-320)$ & $<0.001$ \\
\hline $\begin{array}{l}\text { Technical success } \\
(\%)\end{array}$ & 90.1 & 86.9 & 91.8 & 0.005 \\
\hline $\begin{array}{l}\text { Procedural } \\
\text { success }(\%)\end{array}$ & 88.7 & 85.0 & 90.7 & 0.002 \\
\hline MACE $(\%)$ & 2.4 & 2.9 & 2.2 & 0.42 \\
\hline Death (\%) & 0.4 & 0.4 & 0.4 & 0.88 \\
\hline $\begin{array}{l}\text { Myocardial } \\
\text { infarction (\%) }\end{array}$ & 1.0 & 0.9 & 1.1 & 0.74 \\
\hline Stroke $(\%)$ & 0.3 & 0.0 & 0.5 & 0.14 \\
\hline $\begin{array}{l}\text { Emergency re-PCI } \\
(\%)\end{array}$ & 0.3 & 0.2 & 0.4 & 0.67 \\
\hline $\begin{array}{l}\text { Emergency CABG } \\
(\%)\end{array}$ & - & - & - & - \\
\hline $\begin{array}{l}\text { Emergency } \\
\text { pericardiocentesis } \\
(\%)\end{array}$ & 0.7 & 1.8 & 0.1 & $<0.001$ \\
\hline
\end{tabular}

CABG, coronary artery bypass graft surgery; IVUS, intravascular ultrasound; LVAD, left ventricular assist device; kerma, kinetic energy released per unit mass; MACE, major adverse cardiovascular events; PCI, percutaneous coronary intervention

*

mean \pm standard deviation or median (interquartile range). 


\section{Table 3}

Baseline and angiographic characteristics of lesions approached with antegrade-only techniques, classified according to use of antegrade dissection re-entry.

\begin{tabular}{|c|c|c|c|c|}
\hline Variable & Overall & $\begin{array}{c}\text { Antegrade } \\
\text { Dissection } \\
\text { Re-entry }\end{array}$ & AWE-only & \\
\hline Clinical Characteristics & $n=767$ & $\mathrm{n}=\mathbf{2 4 8}$ & $n=519$ & $p$ \\
\hline Age (years) ${ }^{*}$ & $65.1 \pm 10.3$ & $64.6 \pm 9.8$ & $65.4 \pm 10.5$ & 0.35 \\
\hline Men $(\%)$ & 81.6 & 86.4 & 79.3 & 0.019 \\
\hline Hypertension (\%) & 89.7 & 91.6 & 88.9 & 0.25 \\
\hline Hyperlipidemia (\%) & 94.2 & 95 & 93.9 & 0.53 \\
\hline Diabetes mellitus (\%) & 45.8 & 46.7 & 45.4 & 0.75 \\
\hline Smoking (\%) & 29.6 & 32.1 & 28.5 & 0.002 \\
\hline Heart failure (\%) & 25.1 & 28.6 & 23.4 & 0.13 \\
\hline History of MI (\%) & 40 & 42.3 & 38.9 & 0.38 \\
\hline History of CABG (\%) & 24.4 & 31.3 & 21.1 & 0.003 \\
\hline History of stroke (\%) & 10.4 & 10.5 & 10.4 & 0.97 \\
\hline Prior PCI (\%) & 61 & 63.3 & 59.9 & 0.37 \\
\hline Prior CTO PCI failure (\%) & 15.6 & 20.1 & 13.1 & 0.015 \\
\hline $\begin{array}{l}\text { Peripheral arterial disease } \\
(\%)\end{array}$ & 14.1 & 17.1 & 12.7 & 0.11 \\
\hline Angiographic Characteristics & $n=767$ & $n=248$ & $n=519$ & $p$ \\
\hline CTO target vessel & & & & 0.23 \\
\hline $\mathrm{RCA}(\%)$ & 48.8 & 53.4 & 46.7 & \\
\hline $\operatorname{LCX}(\%)$ & 21.7 & 19.3 & 22.85 & \\
\hline $\mathrm{LAD}(\%)$ & 29.4 & 27.3 & 30.5 & \\
\hline CTO length $(\mathrm{mm}){ }^{*}$ & $28(16-38)$ & $30(22-40)$ & $23(15-34)$ & $<0.001$ \\
\hline $\begin{array}{l}\text { Interventional collaterals } \\
(\%)\end{array}$ & 45.6 & 44.1 & 46.4 & 0.62 \\
\hline $\begin{array}{l}\text { Moderate/severe } \\
\text { calcification }(\%)\end{array}$ & 49.1 & 50.2 & 48.5 & 0.67 \\
\hline $\begin{array}{l}\text { Moderate/severe } \\
\text { tortuosity }(\%)\end{array}$ & 30.7 & 35.2 & 28.3 & 0.06 \\
\hline $\begin{array}{l}\text { Proximal cap ambiguity } \\
(\%)\end{array}$ & 18.5 & 20.1 & 17.6 & 0.48 \\
\hline In-stent restenosis $(\%)$ & 14.5 & 15.8 & 13.8 & 0.49 \\
\hline J-CTO score ${ }^{*}$ & $2.1 \pm 1.2$ & $2.5 \pm 1.1$ & $1.9 \pm 1.2$ & $<0.001$ \\
\hline PROGRESS CTO score * & $1.3 \pm 1.1$ & $1.3 \pm 1.1$ & $1.2 \pm 1.1$ & 0.24 \\
\hline
\end{tabular}

CABG, coronary artery bypass graft surgery; IVUS, intravascular ultrasound; LVAD, left ventricular assist device; MACE, major adverse cardiovascular events; PCI, percutaneous coronary intervention

mean \pm standard deviation or median (interquartile range). 


\section{Table 4}

Procedural characteristics and outcomes of lesions approached with antegrade-only techniques, classified according to use of antegrade dissection re-entry.

\begin{tabular}{|c|c|c|c|c|}
\hline Variable & Overall & $\begin{array}{l}\text { Antegrade } \\
\text { Dissection } \\
\text { Re-entry }\end{array}$ & AWE-only & \\
\hline $\begin{array}{l}\text { Procedural } \\
\text { Characteristics and } \\
\text { Outcomes }\end{array}$ & $n=767$ & $n=248$ & $\mathrm{n}=\mathbf{5 1 9}$ & $p$ \\
\hline IVUS used (\%) & 10.7 & 12.3 & 9.9 & 0.38 \\
\hline Stenting (\%) & 91.7 & 89.7 & 92.6 & 0.18 \\
\hline Number of stents ${ }^{*}$ & $2.3 \pm 1.0$ & $2.7 \pm 1.0$ & $2.1 \pm 1.0$ & $<0.001$ \\
\hline $\begin{array}{l}\text { Hemodynamic support } \\
\text { (LVAD) }(\%)\end{array}$ & 2.3 & 1.1 & 2.8 & 0.22 \\
\hline Fluoroscopy time $(\mathrm{min}){ }^{*}$ & $\begin{array}{c}31.8(20.1- \\
46.6)\end{array}$ & $\begin{array}{c}41.7(28.4- \\
58.4)\end{array}$ & $\begin{array}{l}27.1(17.8- \\
38.4)\end{array}$ & $<0.001$ \\
\hline $\begin{array}{l}\text { Patient air kerma dose } \\
\text { (Gray) }\end{array}$ & $2.6(1.6-4.2)$ & $3.1(2.1-4.7)$ & $2.3(1.4-3.9)$ & $<0.001$ \\
\hline Procedure time $(\min ){ }^{*}$ & $\begin{array}{c}100(67.5- \\
135.5)\end{array}$ & $121(98-159)$ & $87(60-124)$ & $<0.001$ \\
\hline Contrast volume $(\mathrm{ml}){ }^{*}$ & $\begin{array}{c}245(180- \\
318.3)\end{array}$ & $280(210-363)$ & $225(170-300)$ & $<0.001$ \\
\hline Technical success $(\%)$ & 93.7 & 92.7 & 94.2 & 0.43 \\
\hline Procedural success $(\%)$ & 93.3 & 91.8 & 94.1 & 0.23 \\
\hline $\operatorname{MACE}(\%)$ & 1.1 & 2.1 & 0.6 & 0.12 \\
\hline Death $(\%)$ & 0.1 & 0.4 & 0 & 0.32 \\
\hline Myocardial infarction (\%) & 0.3 & 0.8 & 0 & 0.10 \\
\hline Stroke $(\%)$ & 0.3 & 0 & 0.4 & $>0.99$ \\
\hline Emergency re-PCI (\%) & 0.1 & 0 & 0.2 & $>0.99$ \\
\hline Emergency CABG (\%) & - & - & - & - \\
\hline $\begin{array}{l}\text { Emergency } \\
\text { pericardiocentesis }(\%)\end{array}$ & 0.03 & 0.8 & 0 & 0.10 \\
\hline
\end{tabular}

CABG, coronary artery bypass graft surgery; IVUS, intravascular ultrasound; LVAD, left ventricular assist device; kerma, kinetic energy released per unit mass; MACE, major adverse cardiovascular events; PCI, percutaneous coronary intervention

mean \pm standard deviation or median (interquartile range). 


\section{Table 5}

Characteristics of the lesions that were approached using primary vs. secondary/tertiary ADR.

\begin{tabular}{|c|c|c|c|c|}
\hline Variable & Overall & Primary ADR & $\begin{array}{c}\text { Secondary/ } \\
\text { tertiary ADR }\end{array}$ & \\
\hline $\begin{array}{l}\text { Angiographic and } \\
\text { procedural } \\
\text { characteristics and } \\
\text { outcomes }\end{array}$ & $n=458$ & $n=169$ & $n=289$ & $p$ \\
\hline CTO target vessel: & & & & 0.17 \\
\hline RCA $(\%)$ & 64.3 & 69.6 & 61.3 & \\
\hline $\operatorname{LCX}(\%)$ & 14.2 & 10.8 & 16.1 & \\
\hline LAD $(\%)$ & 21.5 & 19.6 & 22.6 & \\
\hline $\mathrm{CTO}$ length $(\mathrm{mm}){ }^{*}$ & $30(20-50)$ & $30(20-50)$ & $38(24.8-56.5)$ & 0.07 \\
\hline $\begin{array}{l}\text { Interventional } \\
\text { collaterals }(\%)\end{array}$ & 54.4 & 61.6 & 50.9 & 0.06 \\
\hline $\begin{array}{l}\text { Moderate/severe } \\
\text { calcification }(\%)\end{array}$ & 60.8 & 53.7 & 64.9 & 0.02 \\
\hline $\begin{array}{l}\text { Moderate/severe } \\
\text { tortuosity }(\%)\end{array}$ & 39.6 & 31.5 & 44.2 & 0.008 \\
\hline $\begin{array}{l}\text { Proximal cap ambiguity } \\
(\%)\end{array}$ & 28.7 & 20.4 & 32.8 & 0.02 \\
\hline In-stent restenosis $(\%)$ & 13.5 & 20.3 & 9.4 & 0.001 \\
\hline J-CTO score ${ }^{*}$ & $2.8 \pm 1.2$ & $2.7 \pm 1.2$ & $2.8 \pm 1.1$ & 0.74 \\
\hline IVUS used (\%) & 50.2 & 42 & 52.5 & 0.19 \\
\hline Stenting (\%) & 84.3 & 91.8 & 79.8 & 0.001 \\
\hline $\begin{array}{l}\text { Hemodynamic support } \\
(\text { LVAD) }(\%)\end{array}$ & 4.4 & 3.5 & 4.9 & 0.78 \\
\hline Procedure time $(\min ) *$ & $\begin{array}{l}156.5(112.3- \\
216.8)\end{array}$ & $116.5(89.3-158)$ & $184.5(127-234)$ & $<0.001$ \\
\hline Contrast volume $(\mathrm{ml}){ }^{*}$ & $310(226-411)$ & $270(200-365)$ & $350(250-442.5)$ & $<0.001$ \\
\hline \multicolumn{5}{|l|}{ Dissection strategy } \\
\hline CrossBoss $(\%)$ & 53.7 & 75.6 & 41 & $<0.001$ \\
\hline $\begin{array}{l}\text { Knuckle wire (\%) } \\
\text { Successful strategy }\end{array}$ & 43.5 & 34.5 & 48.6 & 0.003 \\
\hline CrossBoss (\%) & 33.8 & 51.8 & 23.5 & $<0.001$ \\
\hline Knuckle wire $(\%)$ & 23.6 & 11.3 & 30.7 & $<0.001$ \\
\hline Technical success $(\%)$ & 86.9 & 91.7 & 84.1 & 0.02 \\
\hline $\begin{array}{l}\text { Procedural success } \\
(\%)\end{array}$ & 85 & 90.4 & 81.8 & 0.01 \\
\hline MACE (\%) & 2.8 & 2.4 & 3.1 & 0.78 \\
\hline Death $(\%)$ & 0.4 & 0.6 & 0.3 & $>0.99$ \\
\hline Myocardial infarction (\%) & 0.9 & 0.6 & 1 & $>0.99$ \\
\hline Stroke $(\%)$ & - & - & - & - \\
\hline Emergency re-PCI (\%) & 0.2 & 0 & 0.3 & $>0.99$ \\
\hline Emergency CABG (\%) & - & - & - & - \\
\hline
\end{tabular}




\begin{tabular}{lcccc}
\hline Variable & Overall & Primary ADR & $\begin{array}{c}\text { Secondary/ } \\
\text { tertiary ADR }\end{array}$ & \\
\hline $\begin{array}{l}\text { Emergency } \\
\text { pericardiocentesis (\%) }\end{array}$ & 1.8 & 1.8 & 1.7 & $>0.99$ \\
\hline
\end{tabular}

CABG, coronary artery bypass graft surgery; IVUS, intravascular ultrasound; LVAD, left ventricular assist device; MACE, major adverse cardiovascular events; PCI, percutaneous coronary intervention

mean \pm standard deviation or median (interquartile range). 


\section{Table 6}

Use of the CrossBoss catheter for procedures in which antegrade dissection and reentry was utilized.

\begin{tabular}{|c|c|c|c|c|}
\hline Variable & Overall & CrossBoss & $\begin{array}{l}\text { Wire-based } \\
\text { techniques } \\
\text { only }\end{array}$ & \\
\hline $\begin{array}{l}\text { Procedural } \\
\text { Characteristics and } \\
\text { Outcomes }\end{array}$ & $n=458$ & $n=246$ & $\mathrm{n}=\mathbf{2 1 2}$ & $p$ \\
\hline In-stent restenosis (\%) & 13.5 & 15.9 & 10.6 & 0.10 \\
\hline IVUS used (\%) & 50.2 & 50.0 & 50.4 & 0.95 \\
\hline Stenting $(\%)$ & 84.3 & 88.6 & 78.5 & 0.005 \\
\hline Number of stents* & $2.9 \pm 1.1$ & $2.9 \pm 1.1$ & $3.0 \pm 1.2$ & 0.48 \\
\hline $\begin{array}{l}\text { Hemodynamic support } \\
\text { (LVAD) }(\%)\end{array}$ & 4.4 & 2.6 & 6.7 & 0.07 \\
\hline Fluoroscopy time $(\mathrm{min})^{*}$ & $58.1(37.2-87.1)$ & $51.8(31.4-80.4)$ & $63.8(44.1-97.5)$ & $<0.001$ \\
\hline $\begin{array}{l}\text { Patient air kerma dose } \\
\text { (Gray) }^{*}\end{array}$ & $4.1(2.6-6.0)$ & $3.9(2.3-6.0)$ & $4.2(2.8-6.2)$ & 0.06 \\
\hline Procedure time $(\min )^{*}$ & $\begin{array}{l}156.5(112.3- \\
216.8)\end{array}$ & $\begin{array}{l}144.5(103.5- \\
203.8)\end{array}$ & $\begin{array}{l}175.5(122.3- \\
235.3)\end{array}$ & $<0.001$ \\
\hline Contrast volume $(\mathrm{ml}) *$ & $310(226-411)$ & $300(225-399)$ & $340(240-450)$ & 0.03 \\
\hline Technical success (\%) & 86.9 & 89.8 & 83.5 & 0.045 \\
\hline Procedural success (\%) & 85.0 & 87.2 & 82.3 & 0.14 \\
\hline $\operatorname{MACE}(\%)$ & 2.9 & 3.7 & 1.9 & 0.40 \\
\hline Death $(\%)$ & 0.4 & 0.4 & 0.5 & $>0.99$ \\
\hline Myocardial infarction (\%) & 0.9 & 0.8 & 1.0 & $>0.99$ \\
\hline Stroke $(\%)$ & - & - & - & - \\
\hline Emergency re-PCI (\%) & 0.2 & 0.4 & 0 & $>0.99$ \\
\hline Emergency CABG (\%) & - & - & - & - \\
\hline $\begin{array}{l}\text { Emergency } \\
\text { pericardiocentesis (\%) }\end{array}$ & 1.8 & 2.5 & 1.0 & 0.30 \\
\hline
\end{tabular}

CABG, coronary artery bypass graft surgery; IVUS, intravascular ultrasound; LVAD, left ventricular assist device; kerma, kinetic energy released per unit mass; MACE, major adverse cardiovascular events; PCI, percutaneous coronary intervention mean \pm standard deviation or median (interquartile range). 


\section{Table 7}

Re-entry strategies in all ADR procedures.

\begin{tabular}{lc}
\hline Re-entry Strategies & $\mathbf{n = 4 5 8}$ \\
\hline STAR & 47 \\
\hline Contrast-guided STAR & 0 \\
\hline Mini-STAR & 1 \\
\hline LAST & 7 \\
\hline Stingray & 251 \\
\hline Stick and swap & 82 \\
\hline Bobsled & 8 \\
\hline \multicolumn{1}{c}{ STRAW } & 2 \\
\hline Other & 22
\end{tabular}

STAR, subintimal tracking and re-entry; LAST, limited antegrade subintimal tracking; STRAW, subintimal transcatheter withdrawal. 